\title{
IDENTIFIKASI DAN ANALISIS IMPLEMENTASI SIKA DI PT. PERTAMINA EP PRABUMULIH
}

\author{
IDENTIFICATION AND ANALYSIS OF SIKA IMPLEMENTATION IN \\ PT. PERTAMINA EP PRABUMULIH
}

\author{
Nareshwari, Indriati Paskarini \\ Departemen Keselamatan dan Kesehatan Kerja \\ Fakultas Kesehatan Masyarakat, Universitas Airlangga \\ E-mail: nareshwari2@gmail.com
}

\begin{abstract}
Oil and gas industry have high hazard potential. Some of major hazard in the oil and gas industry are fire hazard, gas explosion, and gas poisoning. PT Pertamina EP Asset 2 Prabumulih Field have Safe Work Permit System (SIKA) to prevent potential hazard in workplace. This research aims to study the SIKA identification and analysis of its implementation in PT Pertamina EP Asset 2 Prabumulih Field. This research was a observational study and conducted with cross sectional approach. Data used in the research are primary data and secondary data. The result obtained from this research was PT Pertamina EP Asset 2 Prabumulih Field have multiple type of SIKA such as SIKA for hot operation, cold operation, digging, and confined space. SIKA form contained about the job description, location, amount of workers, inherent dangers, job requirements such as Job Safety Analysis, personal protective equipment, fire extinguishers, ventilation, etc) and parties that responsible in the SIKA implementation. Implementation that have been observed compared and analyzed with current regulation applied in PT. Pertamina EP Asset 2. Based on the result, implementation of SIKA has gone well. SIKA have not well distributed across the Field. Advice that can be given is the SIKA Document distributed in accordance with the relevant parties.
\end{abstract}

Keywords: identification, analysis, SIKA

\begin{abstract}
ABSTRAK
Industri minyak dan gas bumi memiliki potensi bahaya yang tinggi. Beberapa potensi bahaya utama di industri migas antara lain bahaya kebakaran, ledakan dan keracunan gas berbahaya. Salah satu langkah pengendalian yang dilakukan oleh PT. Pertamina EP Asset 2 Prabumulih Field untuk mencegah potensi bahaya adalah dengan sistem Surat Ijin Kerja Aman (SIKA). Penelitian ini bertujuan untuk mempelajari identifikasi dan analisis implementasi SIKA di PT. Pertamina EP Asset 2 Prabumulih Field. Jenis penelitian ini adalah penelitian observasional dengan pendekatan cross sectional. Data yang digunakan dalam penelitian ini adalah data primer dan data sekunder. Hasil dari penelitian ini adalah bahwa PT. Pertamina EP Asset 2 Prabumulih memiliki beberapa jenis SIKA yaitu SIKA pekerjaan panas, dingin, galian dan ruang terbatas. Formulir SIKA berisi mengenai deskripsi pekerjaan, lokasi, jumlah pekerja, bahaya yang terdapat dalam pekerjaan, persyaratan dalam pekerjaan (JSA, APD, sarana pemadam api, ventilasi dan lain-lain), dan pihak yang bertanggung jawab dalam pelaksanaan prosedur SIKA. Hasil observasi implementasi SIKA di tempat kerja dibandingkan dan dianalisis dengan standar peraturan yang dimiliki oleh PT. Pertamina EP Asset 2 Prabumulih Field. Berdasarkan hasil analisis, pelaksanaan SIKA telah berjalan dengan baik. Dalam pelaksanaannya, pendistribusian SIKA belum berjalan dengan baik. Saran yang dapat diberikan untuk PT. Pertamina EP Asset 2 Prabumulih adalah SIKA didistribusikan sesuai kepada pihak yang terkait.
\end{abstract}

Kata kunci: identifikasi, analisis, SIKA

\section{PENDAHULUAN}

Industri adalah salah tempat yang memiliki risiko yang tinggi. Risiko dapat berasal dari kompleksnya alat kerja yang digunakan, proses kerja yang dilaksanakan maupun dari hasil produksinya.
Risiko yang terdapat di suatu lingkungan kerja akan menimbulkan potensi bahaya.

Menurut Tarwaka (2008) risiko adalah kemungkinan terjadinya kecelakaan dan kerugian pada suatu proses kerja. Setiap sumber yang menimbulkan kecelakaan maupun kerugian dapat 
dikendalikan dengan menggunakan langkah pengendalian risiko.

Menurut Tarwaka (2008) potensi bahaya adalah segala sesuatu yang dapat menyebabkan terjadinya sakit, kecelakaan, kerugian dan kerusakan harta dan benda, bahkan dapat menyebabkan kematian. Potensi bahaya berhubungan dengan proses kerja maupun sistem kerja yang digunakan. Kecelakaan menurut Tarwaka, (2008) adalah peristiwa yang tidak dikehendaki, tidak diduga, maupun diharapkan, tidak terdapat unsur kesengajaan dan perencanaan, disertai dengan kerugian harta benda dan penderitaan yang bersumber dari alat kerja, bahan, dan proses pada suatu industri. Kerugian kecelakaan menimbulkan kerugian fisik dan maupun mental. Potensi bahaya salah satunya disebabkan oleh kesalahan manusia. Menurut Jahangiri et al. (2016) berdasarkan investigasi yang dilaksanakan pada industri yang mengalami kecelakaan, kesalahan manusia berperan besar pada 90\% kecelakaan di industri nuklir, $80 \%$ di industri kimia, $75 \%$ industri maritim, 70\% industri penerbangan.

Salah satu langkah pengendalian risiko yang dapat dilakukan adalah dengan menerapkan sistem ijin kerja. Ijin kerja adalah sebuah sistem yang bertujuan agar pekerja, pemberi ijin kerja, pemberi wewenang kerja dan pimpinan kerja memiliki koordinasi yang baik terhadap aspek keselamatan dalam pekerjaan. Aspek keselamatan dalam pekerjaan harus terpenuhi supaya pekerjaan dapat dilakukan dengan aman dan terhindar dari potensi bahaya. Menurut Reddy (2015), sistem ijin kerja adalah sebuah dokumen yang mengelompokkan pekerjaan sesuai dengan spesifikasi dan bahaya yang terkandung serta langkah pengendaliannya. Dokumen ijin kerja digunakan untuk memastikan pekerjaan aman dilakukan di industri. Menurut Kartika (2013), implementasi sistem ijin kerja akan menurunkan risiko di tempat kerja pada tingkat yang dapat diterima dan mengurangi kemungkinan akan terjadinya kecelakaan, kebakaran, ledakan, kerusakan properti dan kerusakan lingkungan. Menurut Oliver (2010), sistem ijin kerja adalah sebuah sistem yang formal yang digunakan untuk mengendalikan jenis pekerjaan yang mengandung potensi bahaya.

Setiap aspek pekerjaan baik manusia, peralatan, bahan, dan hasil produksi harus dilindungi dengan baik. Undang-Undang Nomor 1 Tahun 1970 menyatakan bahwa "setiap tenaga kerja berhak mendapat perlindungan atas keselamatan dalam melakukan pekerjaan untuk kesejahteraan dan meningkatkan produksi serta produktivitas nasional, bahwa setiap orang yang berada di tempat kerja perlu terjamin pula keselamatannya, bahwa setiap sumber produksi perlu dipakai dan dipergunakan secara aman dan efisien"

Menurut PT. Pertamina (2010), surat ijin kerja adalah sebuah surat ijin atau formulir yang digunakan untuk mengendalikan bahaya suatu pekerjaan dan sebagai sarana koordinasi dan komunikasi antara aspek HSSE antar level manajemen, pengawas hingga pekerja dan pelaksana kerja. Menurut Syakhroni (2007), sistem ijin kerja aman adalah sebuah prosedur yang harus dipatuhi oleh pihak-pihak yang terlibat dalam pelaksanaan pekerjaan.

Surat ijin kerja diberlakukan pada pekerjaan yang mengandung sumber bahaya. Sumber bahaya harus dikendalikan sedemikian rupa supaya tidak menyebabkan cidera, kematian, penyakit akibat kerja, kerusakan peralatan dan pencemaran terhadap lingkungan. Selain itu, sistem ijin kerja merupakan sistem resmi yang dipergunakan untuk mengendalikan pekerjaan yang memiliki potensi bahaya.

Tujuan dari sistem ijin kerja adalah untuk pencegahan kecelakaan melalui pengawasan secara langsung pekerjaan di lapangan, sebagai dokumen sah tentang prosedur kerja, sarana pertanggungjawaban dari setiap komponen kerja di tempat dan lokasi yang mengandung potensi bahaya serta untuk menjembatani ketimpangan komunikasi antara setiap pihak di tempat kerja yang mengandung potensi bahaya.

Ijin kerja di tempat kerja memiliki beberapa jenis. Jenis digolongkan berdasarkan pekerjaan yang dilakukan. Menurut Syukri (1997) dalam Prasetyaningrum (2011), ijin kerja terdiri dari ijin kerja dingin, ijin kerja penggalian, ijin kerja melakukan pekerjaan berbahaya dengan menggunakan api, ijin kerja di ruang tertutup, dan ijin kerja pada pekerjaan yang menggunakan energi panas. Terdapat pula nama lain dari sistem ijin kerja meliputi; ijin kerja panas; ijin kerja dingin, ijin kerja masuk dalam ruang tertutup seperti pada bejana dan tangki, ijin kerja penggalian dan ijin kerja listrik.

Menurut PT. Pertamina (2010), formulir ijn kerja berisi beberapa komponen antara lain sebagai berikut: nama pekerjaan dan ruang lingkupnya; tempat pekerjaan dilakukan; penanggungjawab pekerjaan; pembuat ijin kerja, pemberi ijin kerja dan penerbit ijin kerja; persyaratan keselamatan dan dokumen pendukung yang diperlukan; tanggal 
dan waktu pekerjaan akan dilakukan; masa berlaku ijin kerja; tanggal dan waktu pekerjaan selesai dilaksanakan; serta diterimanya surat ijin kerja oleh pihak yang berwenang sehubungan dengan telah selesainya pekerjaan.

PT. Pertamina adalah sebuah perusahaan yang bergerak di bidang hulu produksi minyak dan gas bumi yang mana kegiatannya adalah eksplorasi, eksploitasi dan produksi minyak gas bumi. Lokasi PT. Pertamina terletak di seluruh wilayah Indonesia. Salah satunya adalah PT. Pertamina EP Asset 2 yang berlokasi di Prabumulih Sumatera Selatan. Jumlah produksi minyak per hari adalah 8.000 Barrel Oil Per Day, sedangkan produksi gasnya adalah sejumlah 177,1 MMSCFD. PT. Pertamina Asset 2 Prabumulih Field merupakan Field terbesar di Indonesia yang mana memiliki 20 stasiun pengumpul, 6 stasiun kompresor gas, 11 buah rig perawatan sumur. PT Pertamina EP sebagai perusahaan bisnis eksplorasi dan produksi minyak dan gas bumi mempunyai visi menjadi perusahaan kelas dunia. Salah satu strateginya adalah dengan mewujudkan aspek Health, Safety, Security and Environment (HSSE) dalam setiap kegiatan.

PT. Pertamina EP Asset 2 Prabumulih Field memiliki berbagai macam pekerjaan yang mengandung potensi bahaya. Pekerjaan yang ada di Field Prabumulih ini antara lain pekerjaan welding, cutting, brazzing, grinding, blasting, bekerja di ruang terbatas, pekerjaan penggalian, bekerja di ketinggian, serta pekerjaan lifting dan rigging. Semua jenis pekerjaan tersebut mengandung potensi bahaya yang dapat menimbulkan kecelakaan kerja. Oleh karena itu, untuk mencegah terjadinya kecelakaan kerja maka PT. Pertamina EP Asset 2 Prabumulih Field melakukan pengendalian dan pengawasan pekerjaan dengan menggunakan Surat Ijin Kerja Aman (SIKA). Berdasarkan latar belakang, maka penulis tertarik untuk membahas mengenai identifikasi dan analisis implementasi Surat Ijin Kerja Aman (SIKA) di PT. Pertamina EP Asset 2 Prabumulih Field.

\section{METODE}

Jenis penelitian yang dilakukan adalah penelitian observasional. Data hasil observasi disajikan dalam bentuk naratif. Berdasarkan tempat penelitian, maka penelitian ini termasuk observasi lapangan. Berdasarkan waktu pengambilan data, maka penelitian ini menggunakan pendekatan cross sectional study. Penelitian ini dilaksanakan di PT. Pertamina EP Asset 2 Prabumulih Field, Sumatera
Selatan. Data diambil pada bulan September sampai dengan bulan Oktober 2016.

Data yang digunakan dalam penelitian ini adalah data primer dan data sekunder. Data primer diperoleh dari observasi langsung dan wawancara kepada pihak yang terkait dengan pembuatan SIKA. Data sekunder diperoleh dari dokumen perusahaan. Observasi dan wawancara untuk mengetahui identifikasi dan analisis implementasi Surat Ijin Kerja di perusahaan dilakukan terhadap HSSE Staff dan HSE Koordinator.

\section{HASIL}

\section{Gambaran Umum PT. Pertamina EP Asset 2 Prabumulih Field}

PT. Pertamina EP Asset 2 Prabumulih Field adalah salah satu perusahaan yang bergerak dalam usaha hulu produksi minyak dan gas bumi yang kegiatan utamanya adalah eksplorasi dan eksploitasi minyak bumi, gas, pengelolaan transportasi pipa migas, jasa pemboran, dan pengelolaan portofolio di sektor hulu, dan panas bumi. Jenis kegiatan utama yang terdapat di PT. Pertamina EP Asset 2 Prabumulih Field adalah kegiatan eksplorasi dan eksploitasi. Eksplorasi adalah kegiatan untuk mencari dan memperoleh cadangan minyak dan gas di tempat yang baru. Kegiatan eksploitasi adalah kegiatan untuk membuat lubang atau sumur minyak dan gas sebagai sarana pengambilan minyak dan gas dengan menggunakan peralatan. PT. Pertamina memiliki beberapa lokasi produksi minyak dan gas bumi yang terdiri dari tiga distrik produksi minyak, satu distrik produksi gas dan pusat pengumpul yang terdiri dari 2 stasiun pengumpul minyak.

PT. Pertamina EP Asset 2 Prabumulih Field mempunyai beberapa proses pengolahan minyak. Minyak yang terdapat di sumur akan dialirkan ke permukaan secara alamiah atau dipompakan dengan mesin. Dari permukaan sumur akan dialirkan ke separator yang bertujuan untuk memisahkan gas, minyak, dan air kemudian minyak dan air dialirkan ke flow line melalui pipa ke stasiun pengumpul (SP) terdekat. Dari stasiun pengumpul (SP) proses selanjutnya adalah dipompakan ke pusat pengumpul produksi (PPP). Di Pusat Pengumpul Produksi akan diinjeksikan bahan chemical untuk memisahkan minyak mentah dengan air dan zat pengotor lainnya kemudian disimpan di tangki-tangki agar lumpur yang terkandung dalam minyak mengendap di bawah. Setelah minyak mentah sudah memenuhi kriteria pengiriman maka langsung dipompakan 
melalui trunk line ke Kilang Minyak 3 Plaju yang kemudian dilakukan pertukaran minyak mentah yang dikirim ke kilang pengolahan di Plaju. Satuan yang digunakan untuk perhitungan crude oil adalah barel per hari. Crude oil yang telah diperoleh pada proses pertambangan langsung di kirim ke stasiun pengumpul atau yang biasa disebut dengan Pusat Pengumpul Produksi (PPP).

\section{Identifikasi Pihak yang Terkait dalam Pembuatan Surat Ijin Kerja Aman (SIKA) di PT. Pertamina EP Asset 2 Prabumulih Field}

Terdapat beberapa personil yang terlibat dalam pelaksanaan sistem Surat Ijin Kerja Aman di PT. Pertamina EP Asset 2 Prabumulih Field. Beberapa personil yang terlibat dalam penyusunan dan pelaksanaan Surat Ijin Kerja Aman serta beberapa personil yang mendukung keamanan pekerjaan antara lain peminta ijin yaitu pengawas pekerjaan yang ditunjuk dan ditugaskan dari dalam atau luar fungsi di lingkungan Pertamina EP. Pimpinan peminta ijin yaitu atasan peminta ijin dari lingkungan PT. Pertamina EP. Pemegang ijin, adalah pelaksana pekerjaan baik dari pekerja atau mitra kerja ataupun kontraktor PT. Pertamina EP. Pemberi ijin, adalah pekerja PT. Pertamina EP yang menjadi Asset Holder yang bertanggung jawab atas asset yang menjadi obyek pekerjaan dan berpotensi untuk terjadinya insiden terhadap asset.

Petugas keselamatan yang mendukung keamanan selama pekerjaan antara lain: fire watcher, petugas uji gas (gas tester), pengawas masuk (entry supervisor), petugas diijinkan (authorized entrant), pengamat masuk (entry watcher), petugas penyelamat, civil engineer, pengawas dan pelaksana pekerjaan, rescue personel, pengawas pekerjaan serta petugas berkualifikasi untuk memeriksa scaffolding dan sarana bekerja lain di ketinggian.

\section{Identifikasi Formulir dan Jenis Surat Ijin Kerja Aman (SIKA) di PT. Pertamina EP Asset 2 Prabumulih Field}

Formulir Surat Ijin Kerja Aman di PT. Pertamina EP berisi tentang deskripsi lokasi pekerjaan yang terdiri dari lokasi; jumlah pekerja; dan pihak yang menjadi pemegang ijin, jenis isolasi yang dibutuhkan, bahaya yang terdapat dalam pekerjaan, persyaratan yang diperlukan seperti JSA; pemadam api; kelengkapan peralatan kerja; ventilasi; APD; pasokan udara; safety harness; grounding; barriers; monitoring $\mathrm{H}_{2} \mathrm{~S}$; alat bantu pernapasan dan personel pengawas, kolom tanda tangan untuk peminta ijin, kolom tanda tangan pemimpin peminta ijin, kolom penerbitan, masa berlaku ijin, persetujuan dari pemegang ijin, kolom pengalihan pekerjaan yang berisi pemegang ijin lama dan baru dan waktu perubahan pekerjaan, pelepasan isolasi yang berisi isolasi listrik; mekanik; hidrolik dan pneumatik, penghentian ijin sementara yang disertai dengan alasan penghentian dan pihak yang menghentikan pekerjaan, kolom keterangan pekerjaan telah selesai serta kolom penutupan ijin yang berisi alasan pekerjaan telah selesai.

Surat Ijin Kerja Aman di PT. Pertamina EP Asset 2 Prabumulih Field terdiri dari ijin kerja umum dan ijin kerja khusus. Ijin kerja umum yaitu ijin kerja yang di dalamnya terdapat lebih dari satu jenis pekerjaan. Masa berlaku SIKA umum maksimal 30 hari kalender. SIKA umum juga diberlakukan untuk pekerjaan yang melibatkan lebih dari satu kontraktor. Ijin kerja khusus yaitu surat ijin kerja yang di dalamnya hanya terdiri dari satu pekerjaan saja (kerja panas, kerja dingin, kerja galian, radiografi maupun pekerjaan berisiko lainnya). Masa berlaku SIKA khusus selama maksimal 7 hari kalender. PT. Pertamina EP Asset 2 Prabumulih Field membuat SIKA dalam bentuk carbonize paper berwarna yang terdiri dari: warna putih untuk dokumen asli yang disimpan oleh pemegang izin (di lokasi pekerjaan), warna merah untuk peminta izin, warna biru untuk HSSE, warna kuning untuk pemberi izin (asset holder).

\section{Identifikasi Prosedur Surat Ijin Kerja Aman (SIKA) untuk Pekerjaan Panas}

PT. Pertamina EP Asset 2 Prabumulih Field memiliki pekerjaan panas yang membutuhkan Surat Ijin Kerja Aman. Pekerjaan panas, yaitu pekerjaan yang menggunakan api terbuka atau pekerjaan yang dapat menimbulkan panas atau percikan api yang dapat menyalakan setiap bahan yang mudah terbakar yang dilakukan dalam radius 15 meter dari bahan ataupun sumber yang mudah terbakar selain itu, pekerjaan panas juga menggunakan api tertutup. Contoh pekerjaan yang menggunakan api terbuka seperti: pekerjaan dengan acetylene, welding, brazing, cutting, grinding atau chipping, soldering, blasting, high pressure hydro-jet serta pemakaian peralatan yang menghasilkan api terbuka atau elemen panas. Contoh pekerjaan yang menggunakan sumber api tertutup seperti: penggunaan peralatan listrik non-explosion-proof atau peralatan elektronik 
dengan daya baterai jika tanpa sertifikasi aman, pengoperasian kendaraan bermotor (tenaga baterai atau pembakaran dalam) pada area berbahaya terlarang atau area terdapat uap/gas mudah terbakar, penggunaan peralatan dengan tenaga listrik atau angin yang bisa menimbulkan percikan api serta memicu kebakaran. Surat Ijin Kerja Aman untuk pekerjaan panas disertasi dengan JSA dan lembar kerja panas.

Prosedur pelaksanaan Surat Ijin Kerja Aman untuk pekerjaan panas diawali dengan pengawas pekerjaan yang bertugas untuk melengkapi formulir SIKA dan lembar kerja panas. Surat Ijin Kerja panas harus disertai dengan JSA dan rencana pekerjaan. Formulir SIKA dan lembar kerja panas yang telah diisi kemudian di-review oleh pemberi ijin.

Gas tester yang telah ditunjuk melakukan pengukuran gas awal yang meliputi oksigen, $\mathrm{H}_{2} \mathrm{~S}$, methane dan $\mathrm{CH}_{4}$ serta $\mathrm{CO}$. Gas test dilakukan dua kali pada saat sebelum kerja dan selama pekerjaan berlangsung. Pengukuran gas pada saat pekerjaan berlangsung dilakukan minimal setiap 30 menit. Lokasi pekerjaan juga harus selalu diawasi oleh Fire Watcher. Fire Watcher bertugas untuk memastikan bahwa APAR harus berada dalam kondisi yang layak, tidak kedaluwarsa dan selalu berada di lokasi pekerjaan. Fire watcher harus selalu siaga di lokasi pekerjaan.

Berdasarkan hasil gas test dan kesiapan mitigasi risiko, pemberi ijin berwenang untuk menentukan pekerjaan aman untuk dilakukan atau tidak. Pekerjaan yang tidak aman untuk dilakukan harus dilakukan mitigasi dengan cara melakukan pengukuran gas ulang di lokasi pekerjaan. Bagi pekerjaan yang aman untuk dilakukan maka pemberi ijin langsung dapat menandatangani Surat Ijin Kerja Aman dan lembar kerja panas. Lembar kerja panas dan Formulir SIKA harus selalu terdapat di lokasi pekerjaan.

Pelaksana pekerjaan, pengawas pekerjaan, fire watcher dan gas tester harus selalu memonitor kondisi pekerjaan dan apabila terdapat kemungkinan insiden dan pekerjaan berada dalam kondisi yang tidak aman maka pekerjaan dihentikan. Setelah pekerjaan aman, maka pekerjaan dapat dilanjutkan hingga selesai. Surat Ijin Kerja Aman ditutup jika pekerjaan telah selesai. Lembar kerja panas disatukan dengan Surat Ijin Kerja warna kuning sebagai dokumentasi.

\section{Identifikasi Prosedur Surat Ijin Kerja Aman (SIKA) untuk Pekerjaan Dingin}

Pengertian pekerjaan dingin adalah pekerjaan di atas permukaan tanah yang tidak menggunakan api terbuka, tidak melakukan penggalian, dan lainlain. Di PT. Pertamina EP Asset 2 Prabumulih Field yang termasuk pekerjaan dingin adalah pekerjaan pemindahan peralatan kerja, rig down, rig up atau penyusunan peralatan kerja di sumur minyak serta pekerjaan perbaikan peralatan yang tidak menggunakan sumber panas. Pekerjaan dingin tidak diawali dengan gas tester seperti pekerjaan panas.

Prosedur Surat Ijin Kerja Aman untuk pekerjaan dingin dimulai dengan pengawas pekerjaan mengisi formulir Surat Ijin Kerja Aman. Peminta ijin wajib melampirkan HSE plan dan JSA sesuai dengan jenis pekerja dan risiko dalam pekerjaan yang akan dilakukan. Bagi pekerjaan yang memerlukan rencana kegiatan isolasi, maka rencana tersebut harus dituliskan dalam formulir Surat Ijin Kerja Aman. Selanjutnya, pimpinan peminta ijin menandatangani form surat ijin kerja dan meneruskannya kepada pemberi ijin. Formulir surat ijin kerja dan semua lampirannya diperiksa oleh pemberi ijin serta dilakukan pemeriksaan kondisi tempat kerja untuk memastikan langkah pengendalian risiko. Apabila memenuhi syarat, maka Surat Ijin Kerja Aman ditandatangani dan dikembalikan kepada peminta ijin atau pimpinan peminta ijin.

Surat ijin kerja yang telah ditandatangani oleh pemegang ijin, dikembalikan kepada pimpinan peminta ijin untuk didistribusikan sesuai dengan alur pendistribusian Surat Ijin Kerja Aman. Surat Ijin Kerja Aman dan JSA selanjutnya didistribusikan kepada pemegang ijin, peminta ijin, HSSE dan pemberi ijin sesuai dengan warnanya. Bagi pekerjaan yang memiliki potensi bahaya maka harus dilakukan pengawasan dan mekanisme kontrol yang meliputi LOTO. Pelaksana pekerjaan melakukan pekerjaan apabila mekanisme kontrol terhadap pekerjaan yang berbahaya telah dilaksanakan dengan baik.

Monitoring harian dilaksanakan selama pekerjaan berlangsung. Monitoring harian dilaksanakan oleh pemberi ijin. Penutupan ijin kerja dilaksanakan apabila pekerjaan telah selesai dilakukan. Peminta dan pemegang ijin secara bersama-sama mengajukan penutupan Surat Ijin Kerja Aman kepada pemberi ijin. Bersamaan dengan penutupan ijin kerja, Pemberi ijin memastikan lokasi 
pekerjaan telah berada dalam kondisi aman. Setelah kondisi di lokasi pekerjaan benar-benar aman maka pemegang ijin dan peminta ijin menandatangani kolom pekerjaan telah selesai pada formulir Surat Ijin Kerja Aman. Selanjutnya, pemberi ijin memberikan persetujuan penutupan surat ijin kerja dengan menandatangani kolom penutupan ijin. Surat ijin kerja yang telah ditandatangani kemudian diperbanyak dan didistribusikan kepada peminta ijin dan HSSE staf.

\section{Identifikasi Prosedur Surat Ijin Kerja Aman (SIKA) untuk Pekerjaan Galian}

PT. Pertamina EP Asset 2 Prabumulih Field memiliki pekerjaan galian. Pekerjaan galian adalah pekerjaan pembuatan saluran atau lubang di tanah, baik yang menggunakan alat berat maupun secara manual menggunakan sekop atau cangkul. Termasuk dalam pekerjaan penggalian di PT. Pertamina EP Asset 2 Prabumulih Field adalah: pekerjaan pembuatan saluran pipa, pembuatan gorong-gorong, pembuatan pondasi atau platform, pembuatan kolam air atau water pond.

Surat Ijin Kerja Aman untuk pekerjaan galian dilengkapi dengan JSA dan checklist penggalian. Prosedur pelaksanaan Surat Ijin Kerja Aman untuk pekerjaan galian dimulai dengan melakukan persiapan memulai pekerjaan. Persiapan dilakukan dengan menentukan tipe tanah, melakukan verifikasi apakah ada prasarana bawah tanah di lokasi penggalian, memindahkan seluruh rintangan yang terdapat di permukaan tanah jika ada, dan memeriksa apakah lokasi penggalian terkontaminasi dengan minyak.

Civil engineer yang telah ditunjuk melakukan penentuan sistem pengaman galian yang diperlukan. Tahap selanjutnya adalah pengawas pekerjaan membuat checklist dan mengurus pembuatan Surat Ijin Kerja Aman. Pemberi ijin melaksanakan review kesiapan pekerjaan dengan checklist. Pemberi ijin kerja memberikan ijin pekerjaan penggalian dapat dimulai atau tidak. Bagi pekerjaan yang belum aman maka pemberi ijin memberikan wewenang kepada pengawas untuk melaksanakan mitigasi. Bagi pekerjaan yang telah aman untuk dilakukan maka pemberi ijin menandatangani Surat Ijin Kerja Aman. Selama pekerjaan berlangsung, harus dilakukan monitor secara terus menerus di lokasi pekerjaan. Saat pelaksanaan pekerjaan, jika terdapat kondisi yang membahayakan maka pekerjaan dihentikan. Bagi pekerjaan yang aman, maka pekerjaan dilanjutkan hingga selesai dan SIKA ditutup.

\section{Identifikasi Prosedur Surat Ijin Kerja Aman (SIKA) untuk Pekerjaan Masuk Ruang Terbatas (Confined Space)}

Pekerjaan masuk ruang terbatas di PT. Pertamina EP Asset 2 Prabumulih Field yaitu pekerjaan di dalam ruangan yang memiliki luas dan konfigurasi yang dapat dimasuki manusia dan bekerja di dalamnya namun memiliki akses masuk dan keluar yang terbatas dan tidak dirancang untuk melaksanakan pekerjaan secara kontinu seperti bejana, tangki, paritan dengan kedalaman lebih dari 1,8 m, dan lain-lain yang sejenis. Pekerjaan yang termasuk kerja masuk ruang terbatas adalah pekerjaan pembersihan tangki minyak di stasiun pengumpul, masuk gorong-gorong, terowongan, serta pekerjaan penggalian yang kedalamannya lebih dari 1,8 meter.

Mekanisme pelaksanaan Surat Ijin Kerja Aman untuk pekerjaan di ruang terbatas dimulai dari pengawas pekerjaan mengurus Surat Ijin Kerja Aman. Pengawas masuk melengkapi lembar confined space entry untuk selanjutnya di-review oleh pemberi ijin. Pengawas pekerjaan memastikan peralatan confined space entry yang meliputi ventilasi, respirator, rencana dan sarana penyelamatan tersedia di lokasi pekerjaan serta masih berfungsi dengan baik.

Pekerjaan yang akan dilaksanakan harus dilakukan proses gas tester oleh petugas yang telah ditunjuk untuk melakukan pengukuran gas yang meliputi gas oksigen, $\mathrm{H}_{2} \mathrm{~S}$, methane dan $\mathrm{CH}_{4}$ serta CO. Tujuan dari dilakukannya pengujian gas adalah untuk menentukan keberadaan uap gas atau konsentrasinya sehingga tidak membahayakan pekerja pada saat bekerja. Pekerjaan ruang terbatas di PT. Pertamina EP Asset 2 Prabumulih Field mengandung gas yang mudah terbakar, gas mudah meledak, dan gas yang bersifat toxic bagi pekerja.

Pengujian gas dilaksanakan pada tempat yang diduga terdapat gas yang berbahaya. Metode dari pengujian gas adalah sebelum menggunakan peralatan yaitu gas detector, maka petugas yang akan melakukan pengujian gas harus memahami dan mengerti informasi mengenai alat yang akan digunakan. Selain itu, peralatan uji gas harus terkalibrasi. Tahapan yang harus dilaksanakan sebelum pengujian gas adalah identifikasi zat-zat dan gas-gas yang berbahaya. Pengetesan awal dilakukan setelah area kerja terisolasi dan siap untuk dilakukan deteksi gas. 
Pengetesan gas pada confined space dilaksanakan pada saat sistem ventilasi sudah dimatikan 30 menit sebelumnya. Pengetesan gas dilakukan dengan urutan sebagai berikut: oksigen, gas mudah terbakar, dan gas yang beracun. Pengetesan gas dilakukan terlebih dahulu pada area yang aman kemudian ke area yang diduga terdapat gas berbahaya. Petugas yang melakukan pengetesan gas harus menggunakan alat pelindung diri yang lengkap seperti respirator, atau Self Contained Breathing Aparatus. Saat pengukuran, jika alarm pada alat test berbunyi maka menandakan terdapat gas berbahaya. Jika ditemukan gas berbahaya di lokasi kerja maka area kerja harus dikosongkan hingga kondisi aman seperti sedia kala. Langkah pengendalian terhadap gas berbahaya yang dilakukan oleh PT. Pertamina EP Asset 2 Prabumulih Field adalah dengan memasang blower pada area yang terdapat gas berbahaya.

Pemberi ijin menentukan confined space aman untuk dimasuki pekerja atau tidak. Jika tidak aman maka pemberi ijin meminta kepada pengawas pekerjaan untuk melakukan mitigasi. Apabila pekerjaan aman untuk dilakukan maka pemberi ijin menandatangani Surat Ijin Kerja Aman dan lembar confined space entry.

Setiap personil yang masuk ke dalam ruang terbatas dicatat oleh pengamat masuk dalam lembar confined space entry dan ditandatangani. Lembar confined space entry berisikan nama personil yang masuk, jam masuk ke confined space, dan jam keluar dari confined space. Gas tester tetap melanjutkan monitoring gas di dalam confined space.

Lokasi pekerjaan harus tetap dimonitor oleh pengawas masuk, pengawas pekerjaan, pengamat masuk serta gas tester. Penghentian pekerjaan dilakukan apabila kondisi di dalam confined space dianggap membahayakan dan dilakukan intervensi. Bagi pekerjaan yang aman tetap dilanjutkan hingga selesai dan Surat Ijin Kerja Aman dapat ditutup.

\section{Identifikasi Prosedur Surat Ijin Kerja Aman (SIKA) untuk Pekerjaan di Ketinggian}

Pekerjaan di ketinggian di PT. Pertamina EP Asset 2 Prabumulih Field yaitu pekerjaan yang harus dilakukan di level ketinggian lebih dari 1,8 $\mathrm{m}$ di atas permukaan tanah. Jenis pekerjaan di ketinggian meliputi: bekerja pada mobile elevating work platform, bekerja di tower, bekerja di atas tangki, bekerja di atas scaffolding, dan pekerjaan lain di atas tanah dengan ketinggian lebih dari 1,8 meter. Surat
Ijin Kerja Aman untuk pekerjaan ketinggian disertai dengan JSA dan checklist pekerjaan di ketinggian.

Prosedur pelaksanaan Surat Ijin Kerja Aman untuk pekerjaan ketinggian dimulai dengan identifikasi sarana dan peralatan keselamatan yang dibutuhkan. Identifikasi ini dilakukan oleh pengawas pekerjaan. Salah satu sarana keselamatan yang digunakan pada pekerjaan ketinggian adalah scaffolding. Sesaat sebelum kerja, scaffolding diperiksa oleh pemberi ijin. Bagi pekerjaan yang aman untuk dilakukan, maka pemberi ijin menandatangani Surat Ijin Kerja Aman dan pekerjaan dapat dimulai. Penghentian pekerjaan dilakukan jika terdapat kondisi yang tidak aman dan dilakukan langkah mitigasi. Lokasi pekerjaan harus selalu dimonitor oleh pengawas pekerjaan. Apabila kondisi pekerjaan aman, maka pekerjaan diselesaikan dan Surat Ijin Kerja Aman dapat ditutup.

\section{PEMBAHASAN}

\section{Analisis Implementasi Surat Ijin Kerja Aman (SIKA) untuk Pekerjaan Panas}

Implementasi prosedur Surat Ijin Kerja Aman di PT. Pertamina EP Asset 2 Prabumulih Field kemudian dibandingkan dengan prosedur yang telah dibuat oleh perusahaan yaitu Tata Kerja Organisasi Surat Ijin Kerja Aman dan Kontrol Pekerjaan Berbahaya No.B007/A3/EP8000/2016-S0-Revisi 3.

Pelaksanaan prosedur surat ijin kerja aman di PT. Pertamina EP telah diimplementasikan dengan baik. Hal ini sejalan dengan penelitian yang dilaksanakan oleh Raya et al. (2014) yang meneliti mengenai analisis implementasi sistem ijin kerja panas pada bagian Plantis di PT. Indo Acidatama, Tbk. Perusahaan telah menerapkan prosedur izin kerja panas dengan baik.

Seluruh Surat Ijin Kerja telah dilengkapi dengan lembar kerja panas dan JSA. Setiap pekerjaan panas selalu diawali dengan gas test dan fire watcher selalu siaga di lokasi pekerjaan. Selama pekerjaan berlangsung, lokasi dan pekerjaannya selalu dimonitor. Langkah untuk mencegah bahaya kebakaran dan ledakan telah diterapkan dengan cara melengkapi setiap lokasi pekerjaan dengan alat pemadam api baik alat pemadam api portable maupun sarana pemadam permanen. Contoh alat pemadam api portable yang terdapat di PT. Pertamina EP Asset 2 Prabumulih Field seperti alat pemadam api ringan jenis foam dan dry chemical. 
Sarana pemadam permanen yang terdapat di lokasi kerja antara lain waterpond dan foam chamber.

Pelaksanaan SIKA masih terdapat beberapa kekurangan yaitu pemberi ijin belum mereview lembar kerja panas, rencana pekerjaan, SIKA dan JSA. Pemberi ijin hanya memberikan tanda tangan saja.

\section{Analisis Implementasi Surat Ijin Kerja Aman (SIKA) untuk Pekerjaan Dingin}

Prosedur pelaksanaan Surat Ijin Kerja Aman untuk pekerjaan dingin di PT. Pertamina EP telah dilaksanakan dengan baik. Implementasi yang ada di lapangan kemudian dianalisis dan dibandingkan dengan standar peraturan yang dimiliki oleh perusahaan yaitu Tata Kerja Organisasi Surat Ijin Kerja Aman dan Kontrol Pekerjaan Berbahaya No.B-007/A3/EP8000/2016-S0-Revisi 3.

Pelaksanaan Surat Ijin Kerja Aman secara keseluruhan telah dilaksanakan dengan baik. Personil yang menandatangani Surat Ijin Kerja Aman telah mendapatkan pelatihan yang sesuai melalui Basic Safety Training dan Advance HSE Training. Formulir Surat Ijin Kerja Aman untuk pekerjaan dingin yang telah ditandatangani selalu berada di lokasi pekerjaan dan dibawa pada sat pekerjaan sedang berlangsung. Surat Ijin Kerja Aman telah terdokumentasi dalam log book dan dipegang oleh Asset Holder. Audit Surat Ijin Kerja Aman untuk pekerjaan dingin telah dilaksanakan secara teratur setiap tahun.

Pelaksanaan SIKA di PT. Pertamina EP Asset 2 Prabumulih Field masih memiliki berbagai kekurangan antara lain tidak semua Surat Ijin Kerja Aman didokumentasikan di control room. Pada saat pelaksanaan pekerjaan, formulir Surat Ijin Kerja Aman belum didistribusikan dengan baik kepada pihak terkait. Surat Ijin Kerja Aman yang berjumlah 4 rangkap dipegang oleh pemegang ijin atau pelaksana pekerjaan.

Bagi pekerjaan yang membutuhkan LOTO di PT. Pertamina EP Asset 2 Prabumulih Field terdapat aturan checklist information and conformation untuk pekerjaan yang berbahaya yang berarti bahwa terdapat pekerjaan berbahaya yang membutuhkan sistem penguncian dan pelabelan (LOTO). Namun, jumlah LOTO yang terdapat di tempat kerja jumlahnya kurang. Saran yang dapat diberikan untuk PT. Pertamina EP Asset 2 Prabumulih Field adalah menambah ketersediaan jumlah LOTO di tempat kerja sehingga sistem LOTO dapat berjalan dengan baik.
Berdasarkan Tata Kerja Organisasi, setelah pekerjaan selesai, lokasi pekerjaan harus benar-benar dipastikan aman. Namun pada pelaksanaannya, pemeriksaan hanya dengan spot check dan tidak dilakukan secara menyeluruh.

\section{Analisis Implementasi Surat Ijin Kerja Aman (SIKA) untuk Pekerjaan Galian}

Prosedur implementasi Surat Ijin Kerja Aman untuk pekerjaan galian telah berjalan dengan baik. Hasil observasi di lapangan kemudian dianalisis dan dibandingkan dengan Tata Kerja Organisasi yang dimiliki perusahaan yaitu Tata Kerja Organisasi Surat Ijin Kerja Aman dan Kontrol Pekerjaan Berbahaya No.B-007/A3/EP8000/2016-S0-Revisi 3.Seluruh prosedur telah berjalan dengan baik Persiapan penggalian telah dilaksanakan dengan baik menggunakan checklist, civil engineer telah menentukan dan melaksanakan sistem pengaman galian, kesiapan pekerjaan telah di-review, dan monitor terhadap pekerjaan telah dilaksanakan selama pekerjaan berlangsung.

Setelah pekerjaan selesai dilakukan, lokasi pekerjaan harus diperiksa apakah masih terdapat alat yang masih tertinggal atau terdapat sistem isolasi yang tidak tertutup dengan baik. Namun dalam pelaksanaannya di lapangan, pemeriksaan kondisi lokasi kerja tidak dilakukan secara menyeluruh. Saran yang dapat diberikan adalah sebaiknya setelah pekerjaan selesai dilakukan, lokasi tempat kerja diperiksa dengan baik meliputi pemeriksaan peralatan, pemeriksaan keamanan secara menyeluruh supaya tempat kerja benar-benar dipastikan aman bagi pekerja yang akan bekerja pada shift selanjutnya.

\section{Analisis Implementasi Surat Ijin Kerja Aman (SIKA) untuk Pekerjaan Masuk Ruang Terbatas (Confined Space)}

Hasil observasi implementasi Surat Ijin Kerja Aman Pekerjaan Masuk Ruang Terbatas di PT. Pertamina EP Asset 2 Prabumulih Field kemudian dianalisis dan dibandingkan dengan Tata Kerja Organisasi Surat Ijin Kerja Aman dan Kontrol Pekerjaan Berbahaya No.B-007/A3/EP8000/2016S0-Revisi 3 yang dimiliki oleh perusahaan.

Berdasarkan hasil analisis, masih terdapat beberapa kekurangan dalam pelaksanaan Surat Ijin Kerja Aman untuk pekerjaan memasuki ruang terbatas. Pemberi ijin belum me-review lembar confined space entry. Pemberi ijin kerja hanya 
me-review formulir Surat Ijin Kerja Aman dan JSA. Beberapa SIKA tidak terdokumentasi di control room. Seharusnya Surat Ijin Kerja Aman disusun dan didokumentasikan dengan baik.

\section{Analisis Implementasi Surat Ijin Kerja Aman (SIKA) untuk Pekerjaan Ketinggian}

Untuk mengetahui seberapa baik penerapan Surat Ijin Kerja Aman untuk pekerjaan di ketinggian, hasil observasi di lapangan kemudian dibandingkan dengan Tata Kerja Organisasi yang dimiliki oleh perusahaan yaitu Tata Kerja Organisasi Surat Ijin Kerja Aman dan Kontrol Pekerjaan Berbahaya No.B007/A3/EP8000/2016-S0-Revisi 3 yang dimiliki oleh perusahaan.

Pelaksanaan SIKA pekerjaan di ketinggian masih terdapat beberapa kekurangan antara lain scaffolding dan sarana keselamatan lain sudah diinspeksi oleh HSE. Namun pada saat ini, PT. Pertamina EP Aset 2 Prabumulih Field tidak memilki petugas yang berkualifikasi yang secara khusus melakukan inspeksi terhadap scaffolding dan sarana lainnya.

\section{SIMPULAN}

PT. Pertamina EP Prabumulih Asset 2 Prabumulih Field telah menerapkan Surat Ijin Kerja Aman dalam pelaksanaan pekerjaannya. Surat Ijin Kerja Aman yang di PT. Pertamina EP Asset 2 Prabumulih Field terdiri dari Surat Ijin Kerja Aman untuk pekerjaan panas, Surat Ijin Kerja Aman untuk pekerjaan dingin, Surat Ijin Kerja Aman untuk pekerjaan memasuki ruang terbatas, Surat Ijin Kerja Aman untuk pekerjaan penggalian dan Surat Ijin Kerja Aman untuk pekerjaan di ketinggian.

Prosedur untuk masing-masing Surat Ijin Kerja Aman telah tersusun dan terlaksana dengan baik. Setiap Surat Ijin Kerja Aman di PT. Pertamina EP telah dilengkapi dengan dokumen penunjang, misalnya untuk pekerjaan panas terdapat lembar kerja panas, untuk pekerjaan memasuki ruang terbatas terdapat lembar confined space entry, untuk pekerjaan galian terdapat checklist penggalian. Semua Surat Ijin Kerja Aman yang dibuat telah disertai dengan JSA.

Berdasarkan hasil wawancara dengan HSSE Staf, HSE koordinator dan pihak yang terkait langsung dengan pembuatan Surat Ijin Kerja Aman pembuatan dan pelaksanaan diketahui bahwa implementasi Surat Ijin Kerja Aman di PT. Pertamina EP Asset 2 telah diimplementasikan dengan baik. Setiap personil yang terlibat dalam pembuatan dan pelaksanaan Surat Ijin Kerja Aman telah memiliki pemahaman yang cukup baik terkait alur pelaksanaan Surat Ijin Kerja Aman. Personil yang terkait dengan pembuatan dan pelaksanaan Surat Ijin Kerja Aman di PT. Pertamina EP Asset 2 Prabumulih Field telah mendapatkan Basic Safety Training dan Advanced HSE Training. Salah satu materi yang terdapat di dalam pelatihan tersebut adalah materi mengenai Surat Ijin Kerja Aman. Pada saat Basic Safety Training dan Advanced HSE Training, dilakukan pula pre test sebelum pemberian materi dan post test sesudah materi diberikan.

Kekurangan yang terdapat dalam pelaksanaan SIKA untuk pekerjaan panas, SIKA untuk pekerjaan dingin, SIKA untuk pekerjaan memasuki ruang terbatas, SIKA untuk pekerjaan ketinggian dan SIKA untuk pekerjaan galian adalah pendistribusian yang kurang baik. SIKA yang telah dilaksanakan dan telah ditutup belum didistribusikan kepada masingmasing pihak yang bertanggung jawab. Saran yang dapat diberikan adalah, SIKA diperbanyak dan didistribusikan sesuai dengan warnanya.

\section{DAFTAR PUSTAKA}

Jahangiri, Mehdi. Hoboubi, Naser. Rostamabadi, Akbar. Keshavarzi, Sareh. Hosseini, Ali Akbar. 2016. Human Error Analysis in a Pemit To Work System: A Case Study in a Chemical Plant. Occupational Safety and Health Research Institute. Safety and Health at Work 7 (2016) 6-11: pp. 6-11. Tersedia di: www.e-shaw.org. [26 Januari 2017].

Kartika, S. 2013. Accident Prevention by Using Hazop Study and Work Permit System in Boiler. International Journal of Advanced Engineering Research and Studies. Vol. II/ Issue II/AprilJune, 2013/125-129: pp. 1-5. Tersedia di: Technical Journals Online.com. < http://www. technicaljournalsonline.com/ijaers/VOL\%20II/ IJAERS\%20VOL\%20II\%20ISSUE\%20III\%20 APRIL\%20JUNE\%202013/313.pdf> [26 Januari 2016].

OGP Publication. Guideline on Permit To Work System. 2003. Tersedia di: www.ogp.org.uk/ pubs/189.pdf [2 Oktober 2016].

OHSAS 18001: 2007. Occupational Health and Safety Management System Requirements.

Oliver, A. 2010. Permit to Work: The Integrated Safe System Of Work. APPEA Journal. APPEA Journal 2010 50th ANNIVERSARY ISSUE: pp. 665-679. 
Tersedia di: $<$ https://daks2k3a4ib2z.cloudfront.net/ 54dd3250020c93b11e5e50ad/55120150fc368bb77 f27e325_Permit-to-Work-Integrated-Safe-Systemof-Work-by-Ally-Oliver.pdf> [26 Januari 2017].

Prasetyaningrum, Dyan Ratna. 2009. Penerapan Sistem Ijin Kerja sebagai Upaya Pencegahan Kecelakaan Kerja di PT. APAC Inti Corpora Semarang. Tugas Akhir. Program Diploma III Hiperkes dan Keselamatan Kerja. Universitas Sebelas Maret Surakarta.

PT. Pertamina. 2010. Pengendalian Pekerjaan Berbahaya dengan Dokumentasi. Modul HSE. PT. Pertamina Persero.

Raya, Tomi. Widjasena, Baju. Ekawati. 2014. Analisis Penerapan Sistem Izin Kerja Panas Pada Bagian Plantis di PT. Indo Acidatama, Tbk (Berdasarkan Guidance on Permit to Work Systems tahun 2005). Journal Kesehatan Masyarakat. Volume 2, Nomor 3, Maret 2014: pp. 214-222. Tersedia di: http://ejournal-s1.undip.ac.id/index.php/jkm [26 Januari 2017].

Reddy, Viswanatha Reddy Iragam. 2015. Study of Electronic Work Permit System in Oil and Gas
Industry - Kuwait. International Journal of Innovative Science, Engineering \& Technology. Vol. 2 Issue 4, April 2015: pp. 533-537. Tersedia di: http://ijiset.com/vol2/v2s4/IJISET_V2_I4 77. pdf [26 Januari 2017].

Syakhroni, Akhmad. 2007. Penerapan Manajemen Keselamatan Proses (Cara Kerja Aman) dengan Pendekatan Job Safety Analysis (JSA): Studi Kasus di Unit ITP PT. Pertamina Persero UP - VI Balongan. Transistor. Vol.7 No. 1 Juli 2007: pp. 55-64. Tersedia di : < http://research.unissula.ac.id/ research/file/publikasi/210603031/5052p7106. pdf> [26 Januari 2017].

Tarwaka. 2008. Keselamatan dan Kesehatan Kerja, Manajemen dan Implementasi K3 di Tempat Kerja. Surakarta: Harapan Press.

TKO Surat Ijin Kerja Aman dan Kontrol Pekerjaan Berbahaya No. B007/A3/EP8000/2016-S0 Revisi 3. 2016. PT. Pertamina EP Asset 2 Prabumulih Field.

Undang-Undang Nomor 1 Tahun 1970 tentang Keselamatan Kerja. 